\title{
TURISMO NO ESTADO DO RIO DE JANEIRO: ENSAIO DE UMA TIPOLOGIA*
}

\author{
MigUEL ANGELO RIBEIRO' \\ Universidade Estadual do Rio de Janeiro
}

\begin{abstract}
Para Adyr Balastreri Rodrigues, pioneira dos estudos sobre turismo na geografia brasileira.
\end{abstract}

\section{Considerações iniciais}

“(...) é justamente a diversidade de lugares, regiões, paisagens, territórios, em sua dinâmica, impulsionada pelas demandas sociais, que proporciona uma realidade global fragmentada $\mathrm{e}$ articulada, pulverizada de particularismos e singularidades em conexão com o geral" (LUCHIARI, 1998: 16).

O Estado do Rio de Janeiro, unidade federada localizada na Região Sudeste, caracteriza-se por apresentar enorme diversidade de situações topográficas e climáticas, bem como grande variedade de condições histórico-culturais. Isto posto,

\footnotetext{
* Gostaria de externar meus sinceros agradecimentos ao geógrafo Thiago Ramos Machado, pela elaboração do abstract, dos quadros e da digitação do texto, bem como à Ana Maria Fernandes da Costa, pela leitura crítica e contribuiçōes enriquecedoras para a redação final. As imperfeições verificadas, no entanto, são de inteira responsabilidade do autor.

Professor Adjunto do Departamento de Geografia da Universidade do Estado do Rio de Janeiro - Campus Maracanã/Rio de Janeiro.
} 
a atividade turística se reveste de grande importância como fator de interiorização do desenvolvimento econômico e social, considerada, atualmente uma expressão das mais autênticas do processo de globalização. $\mathrm{O}$ fenômeno do turismo expandese em âmbito planetário até as regiões mais remotas, não desconsiderando nenhum território, e neste contexto, o Brasil encontra-se inserido nesta economia globalizada através da atividade do turismo, quer em decorrência de suas mais diversas paisagens, dentre elas as tropicais, como também em seus diferentes aspectos culturais e históricos, tornando-se na América Latina uma das principais áreas receptoras desses fluxos.

Sendo assim, o Estado do Rio de Janeiro é uma das unidades federadas que apresenta importância para a promoção do turismo brasileiro, atividade esta que merece destaque no contexto do desenvolvimento econômico de nosso estado.

Para se ter uma idéia do papel da atividade turística no Estado do Rio de Janeiro, segundo pesquisas anuais da Embratur, para o ano de 1998, de um total de 4.818.084 de turistas internacionais desembarcados no Brasil, 15,2\% (734.026 turistas) chegaram por este estado, que ocupa a terceira colocação como um dos principais portões de entrada, somente suplantado por São Paulo e Rio Grande do Sul, que receberam, respectivamente, $26,0 \%$ e $19,7 \%$ (EMBRATUR, 1999).

Quanto às cidades brasileiras mais visitadas por turistas internacionais, a capital do Estado, a cidade do Rio de Janeiro, para o ano de 1998, recebeu 1.455 .061 visitantes, correspondendo a 30,2\% do total nacional, enquanto Armação dos Búzios, cidade localizada no litoral norte-fluminense, registrou $260.176(5,4 \%)$, ocupando a oitava posição entre as cidades brasileiras mais visitadas (EMBRATUR, 1999).

Dados mais atualizados registraram para o ano de 2000, segundo matéria publicada no JORNAL DO BRASIL (2001), a entrada de mais de 8 milhões de turistas na cidade do Rio de Janeiro, sendo 2.135 .000 estrangeiros e 6.100 .000 nacionais.

Enquanto o Brasil, no período 1999-2000 cresceu 91,0\%, a cidade do Rio de Janeiro acusou crescimento no total de turistas da ordem de $104,0 \%$.

Quanto aos turistas nacionais, segundo o documento Plano Diretor de Turismodiagnóstico preliminar, elaborado pela TurisRio (1999), o território fluminense recebeu no ano de 1995, um total de mais de 2.900 .000 turistas, o que representou $22,1 \%$ do total de visitantes recebidos pelo Estado naquele ano, provenientes, principalmente, do próprio Estado do Rio de Janeiro, de São Paulo e de Minas Gerais, correspondendo, respectivamente, a $33,7 \%, 33,6 \%$ e $10,9 \%$.

Tais resultados ratificam o papel do Estado do Rio de Janeiro como uma das principais unidades receptoras de turistas nacionais e internacionais, apresentando importância para a promoção do turismo brasileiro.

Neste sentido, o objetivo principal desse artigo é o de analisar os elementos condicionantes para o desenvolvimento da atividade turística em território fluminense, além de elaborar uma tipologia para as 41 localidades (sedes municipais - cidades e sedes distritais - vilas) com função turística, selecionadas a partir do Guia Quatrơ Rodas, da Editora Abril (1999). 


\section{CONDICIONANTES PARA O DESENVOLVIMENTO DA ATIVIDADE DO TURISMO NO ESTADO DO RIO DE JANEIRO}

A atividade turística não pode ser pensada sem as bases geográficas e, neste contexto, podemos distinguir três condicionantes que influenciam o desenvolvimento da atividade do turismo em território fluminense. Tais condicionantes estão intimamente relacionados. São eles: (a) o elemento físico ou natural; (b) o elemento histórico e as atividades econômicas; e (c) o papel dos transportes. Devido à brevidade deste artigo, cada um dos elementos será caracterizado de forma simplificada.

\section{O elemento físico ou natural}

O quadro físico fluminense apresenta-se muito diversificado, em contraponto à limitada extensão territorial (CIDE, 1997). Neste sentido, o Estado do Rio de Janeiro configura uma sucessão de paisagens, cujo alinhamento segue, aproximadamente, a direção geral SW-NE, dominada pela disposição do relevo, que condiciona, em grande parte, a variedade do clima e da cobertura vegetal, entre outros elementos. Sendo assim, distinguem-se como principais unidades físicas: o trecho litorâneo, o conjunto montanhoso e o planalto ondulado até o Vale do Paraíba.

i - O trecho litorâneo, abrange a linha costeira e a região das baixadas, em direção à parte setentrional do estado, constituído por lagoas e cordões litorâneos, com vegetação de restinga. Parte desta área integra a região turística denominada Costa do Sol iniciando-se nos limites da Área Metropolitana (município de Maricá) até o município de Rio das Ostras; e a parte meridional, de constituição rochosa e muito recortada em baías e enseadas, prolongando-se até o município de Parati. Este litoral apresenta-se afogado, estreito e alto, constituindo-se na chamada Costa Verde, a partir do município de Mangaratiba até o município de Parati. Nesta unidade física, a modalidade de turismo mais desenvolvida é a do aproveitamento das praias e das práticas náuticas.

ii - O conjunto montanhoso da Serra do Mar, representado pela frente escarpada e seu reverso, atravessando quase todo o estado, com altitudes até 2000 metros (Serra dos Órgãos), em alguns pontos, é caracterizado por temperaturas mais amenas, quando comparado com as demais unidades físicas, imprimindo características peculiares às diferentes modalidades turísticas. Esta porção é conhecida como Região Serrana.

iii - Por fim, distingue-se o planalto ondulado, que perde altitude até o Vale do Paraíba do Sul, sendo que o rio de mesmo nome representa o traço mais marcante nessa paisagem, cortando o território fluminense de sul para norte, formando uma depressão encaixada entre as escarpas das serras do Mar e da Mantiqueira, esta exibindo o paredão do Pico das Agulhas Negras, com aproximadamente $2800 \mathrm{~m}$ de altitude, muito aproveitado para diferentes modalidades de turismo. 
Esse quadro físico constitui-se em suporte material para a organização econômica e social fluminense, estando diretamente associado ao desenvolvimento da atividade do turismo, exercendo influência na produção de lugares para o consumo.

\section{O elemento histórico e as atividades econômicas}

O elemento histórico e as atividades econômicas são importantes condicionantes para o desenvolvimento da atividade turística. Neste sentido, de modo geral, podemos analisar a ocupação do atual Estado do Rio de Janeiro pelos portugueses a partir do século XVI.

O século XVI marca a descoberta da faixa litorânea do Estado, pela expedição em que tomou parte Américo Vespúcio (1501-1502), sendo que em 1503 é instalada uma feitoria na futura cidade de Cabo Frio, enquanto em 1565 é fundada a cidade do Rio de Janeiro. Sendo assim, formas pretéritas criadas no século XVI ainda persistem nestes espaços e são testemunhos importantes para a preservação da memória e da cultura.

Este século é marcado pela Coroa Portuguesa com a ocupação do litoral, como defesa e conquista da terra (RAHY, 1999), destacando-se a importância do sítio, ou seja, o local no qual estabeleceram-se as futuras cidades, geralmente ocupando a entrada de baías, rios etc, com a presença de inúmeras fortificações, como as encontradas na Baía de Guanabara.

$\mathrm{O}$ século XVII vai ser marcado pelas experiências agrícolas vinculadas à produção de cana-de-açúcar e seus engenhos no Norte Fluminense ou mesmo nos arredores da capital. Esta atividade marca a paisagem dessa região até os dias atuais, encontrando-se fazendas dos antigos barões do açúcar e usinas; enquanto na área metropolitana, pelas grandes transformações ocorridas, poucos vestígios foram deixados na paisagem.

Nu céculo XVIII, com a descoberta das reservas auríferas das Minas Gerais, a organização do povoamento fluminense vai ser profundamente alterada. A exploração do ouro influencia indiretamente na ocupação do território. Concomitante à exploração aurífera nas Minas Gerais, nos primeiros anos desse século, a cana-deaçúcar atinge definitivamente a baixada campista, na porção norte do Estado.

Quanto à atividade aurífera mineira, as cargas do referido metal desciam do planalto das Minas Gerais em lombos de burros, na direção de Parati (Caminho Velho) e eram conduzidos por mar até o Rio de Janeiro.

O Rio de Janeiro se torna rapidamente o principal porto e a mais ativa cidade do país, ao mesmo tempo, a atividade aurífera contribui para o aparecimento de vilas embriões para futuras cidades - que serviam de passagem para o interior, como Vassouras, Paraíba do Sul e Paty do Alferes, entre outras (RAHY, op. cit).

No século XVIII, do ponto de vista histórico e político, merece destaque para a antiga Província do Rio de Janeiro, a transferência da sede do governo colonial de Salvador para o Rio de Janeiro (1763), em decorrência do comércio do ouro das Minas Gerais, além das condições geográficas. 
Cumpre lembrar que no período compreendido entre os séculos XVII e XVIII, os portos tiveram importância fundamental na história econômica fluminense, primeiramente com o transporte de cana-de-açúcar, e logo em seguida com o ouro.

O início do século XIX vai ser marcado, primeiramente, pela extinção do ouro das Minas Gerais (decadência da mineração), enquanto a cana-de-açúcar volta a concentrar, mas por pouco tempo, todas as atenções.

Outro fato histórico e político importante para o atual Estado do Rio de Janeiro e mais diretamente para a cidade do Rio de Janeiro, vai ser a chegada da Corte Portuguesa, em 1808, que afetará a estrutura organizacional da urbe carioca. Em 1834, a cidade do Rio de Janeiro separou-se de sua província e a capital imperial foi elevada à condição de Município Neutro, enquanto a cidade de Niterói tornou-se capital da Província, em 1835 (RIBEIRO, 2001).

A medida que o Império se consolidava, surgia um novo produto-rei na economia fluminense: o café. Esta nova cultura de base exportadora começa o seu trajeto na cidade do Rio de Janeiro, mais precisamente no Maciço da Carioca, nas encostas de Jacarepaguá, além dos Maciços da Pedra Branca e Mendanha. Foi plantado em várias áreas do território fluminense, embora não tenha obtido o resultado esperado, em decorrência da declividade do terreno e das condições climáticas. Mas a maior expressão cafeeira da antiga província iria ocorrer quando, a partir do Mendanha, a rubiácea atingiu São João Marcos (parte do atual município de Rio Claro), Piraí e Resende, chegando, portanto, ao Vale do Paraíba, em seu trecho médio.

O café, no Médio Paraíba Fluminense, teve seu plantio expandido para várias direções, sendo cultivado ao norte em Entre Rios (atual município de Três Rios), seguindo para Nova Friburgo e Cantagalo, na Região Serrana, terminando sua expansão em Itaocara e São Fidélis, seguindo a direção da Zona da Mata Mineira e do Espírito Santo.

As encostas foram ocupadas com cafezais e o fundo dos vales com as sedes das fazendas e instalações de beneficiamento do produto. Atualmente, muitas destas fazendas, principalmente aquelas localizadas no Médio Paraíba, nos municípios de Vassouras, Valença, Paraíba do Sul, entre outros, estão sendo resgatadas para a atividade turística

Os elementos históricos na paisagem, muitos deles, fruto das atividades econômicas desenvolvidas em território fluminense, representam importantes marcos no processo de ocupação, e que hoje podem ser resgatados como elementos culturais e da memória de um povo, constituindo-se em vetores das diferentes modalidades de turismo.

\section{O papel dos transportes}

Os transportes são importantes aliados para o desenvolvimento da atividade do turismo. Estes sistemas de engenharia são relevantes no sentido de promoverem a rapidez dos deslocamentos e das comunicações. 
Para o Estado do Rio de Janeiro, os mesmos tiveram papel preponderante, no tocante a expansão do turismo interno, primeiramente com a difusão das estradas de ferro, à partir de $1854 \mathrm{e}$ impulsionadas com o esplendor da cultura cafeeira, a partir de 1870 , e principalmente com o advento das rodovias, iniciadas no final da década de 1940.

As rodovias tiveram papel vital para a expansão do turismo em território fluminense, concretizando-se, notadamente a partir da década de 1970, com a construção da Ponte Presidente Costa e Silva, ligando as duas principais cidades do Estado, Rio de Janeiro e Niterói; a abertura da BR-101; além da duplicação das rodovias Presidente Dutra (BR-116) e da Washington Luís (BR-040), ligando a capital do Estado, as cidades mineiras de Juiz de Fora e Belo Horizonte.

Com a implantação da BR-101 em território fluminense, além da construção da Ponte Rio-Niterói, concretizada em 1974, a tendência foi haver uma expansão da atividade turística em direção ao litoral sul (Costa Verde) e ao litoral norte (Costa do Sol). Esses são dois grandes vetores de expansão do turismo litorâneo, secundados pela BR-116 (Rodovia Presidente Dutra) que corta a região do Vale do Paraíba.

A duplicação e melhoramento desses eixos de transporte vieram a contribuir de forma positiva para o desenvolvimento da atividade turística em terras fluminenses, principalmente para os municípios localizados externamente à metrópole, tanto os litorâneos, como também os do interior. Tal fato, associado aos oụtros elementos, como o quadro natural diversificado, e aos condicionantes históricos ensejaram a difusão da atividade turística por alguns municípios fluminenses, tornando-os verdadeiros lugares para o consumo.

\section{TIPOLOGIA DOS MUNICÍPIOS COM ATIVIDADES TURÍSTICAS E DE APOIO NO ESTADO DO RIO DE JANEIRO}

A partir do Guia Quatro Rodas (Editora Abril, 1999) ${ }^{2}$ foram selecionadas as localidades classificadas como de função turística pelo referido guia (cidades em estância, histórica, praia e serra), abarcando um total de 30 localidades ${ }^{3}$, bem como daquelas incluídas na referida obra, mas não classificadas como de função turística, além das classificadas como de apoio à mencionada atividade ${ }^{4}$. Sendo assim, o universo da pesquisa engloba 41 localidades (sedes municipais e vilas) localizadas em diferentes regiões fluminenses.

\footnotetext{
${ }^{2}$ Este guia é uma obra de grande relevância para aqueles que viajam pelo Brasil. Nele constam as principais localidades turísticas, além de outras indicaçōes importantes, como restaurantes, comidas típicas, sugestōes de compras, eventos, classificação da hospedagem etc.

${ }^{3}$ Adotou-se a terminologia localidade, em decorrência do referido guia apresentar em sua classificação sedes municipais (cidades) e vilas (sedes distritais).

${ }^{4}$ As localidades classificadas como de apoio apresentam infra-estrutura de suporte ao turismo, apesar de não apresentarem atrativos, nem terem experimentado um processo de turistificação.
} 
Cumpre mencionar que o objetivo metodológico da pesquisa fundamenta-se na visão de um geógrafo procurando trabalhar uma tipologia, tendo como unidade espacial os municípios fluminenses, sem preocupação na utilização de projetos e classificações do Governo Federal ou Estadual.

Em se tratando de uma tipologia na qual há predominância das diferentes modalidades turísticas, passíveis de mudança com o tempo, não corresponde a uma classificação estática, mas passível de mudanças. Neste contexto, para a elaboração da tipologia, levou-se em consideração três elementos, a saber: (a) a classificação da função turística, segundo o Guia Quatro Rodas (1999); (b) as atrações; e (c) os diferentes tipos de hospedagem. Quanto aos tipos de hospedagem, foram caracterizadas: as pousadas, os hotéis-fazenda e os hotéis denominados de comuns.

A partir de uma análise dos elementos selecionados, foi elaborada a tipologia, distinguindo-se cinco grandes tipos, além das localidades de apoio. Sendo assim, destacam-se localidades com funções (tipos) ${ }^{5}$ : 1- Litorânea; 2- Histórica/Rural; 3 Rural/Ecológica/Aventura; 4- Estância/Rural; e 5- Cultural/Rural; além de 6- Apoio ao Turismo (QUADRO 1).

\section{QUADRO 1 \\ TIPOLOGIA DAS FUNÇÕES TURÍSTICAS}

\begin{tabular}{|l|l|}
\hline TIPOS (FUNÇÕES) & SUB-TIPOS \\
\hline 1 - Litorânea & 1.1 - Diversificada \\
& 1.2 - Praia-Náutica/Rural \\
& 1.3 - Praia-Náutica \\
& $1.4-$ Praia-Náutica/Histórica \\
\hline 2 - Histórica/Rural & \\
\hline 3 - Rural/Ecológica/Aventura & 3.1 - Diversificada \\
& 3.2 - Rural \\
& 3.3 - Rural/Ecológica/Aventura \\
\hline 4 - Estância/Rural & \\
\hline 5 - Cultural/Rural & \\
\hline 6-Apoio ao Turismo & \\
\hline
\end{tabular}

Fonte: Guia Quatro Rodas. Brasil. São Paulo: Editora Abril, 1999.

Elaborado por: RIBEIRO, M. Angelo, 2000/2001.

\footnotetext{
${ }^{5}$ Os tipos estão associados às diferentes modalidades, não preocupando-se com uma discussão conceitual das mesmas.
} 


\section{Litorânea}

Engloba municípios localizados no litoral fluminense, distinguindo-se quatro subtipos:

1.1- Diversificada: conjuga uma série de modalidades do turismo: praia-náutica, rural, ecológico, aventura e histórico-cultural.

1.2- Praia-Náutica/Rural: localidades com atividades no litoral e no interior. Conjugam o tipo náutico no litoral, e rural no interior (fazendas, pesque-pague). Aproveitamento, de fixos sociais ${ }^{6}$, em áreas rurais, como antigos engenhos de açúcar e usinas, bem como de estabelecimentos rurais com antigas sedes de fazendas (pecuária e cultivo de cítricos).

1.3- Praia-Náutica: predominam atividades turísticas que conjugam o trinômio sol-céu-mar com diversas modalidades náuticas.

1.4- Praia-Náutica/Histórica: conjugam atividades de praia e náuticas, bem como apresentam fixos históricos que marcam suas paisagens, através de casarios coloniais, igrejas, fortes, solares, entre outros.

\section{Histórica/Rural}

Este tipo agrega municípios localizados em áreas serranas com a presença de fixos históricos como igrejas, museus, casarios, além de em seus espaços rurais agregarem fazendas ligadas ao ciclo cafeeiro (revalorizadas para a atividade do turismo, e muitas vezes, recriadas como verdadeiros simulacros). Ainda distinguimos hotéisfazenda, com atividades voltadas para a vida rural: caminhadas, pesque-pague, cavalgadas entre outros.

\section{Rural/Ecológica/Aventura}

Engloba municípios localizados no interior fluminense, distinguindo-se três subtipos:

3.1- Diversificada: localizadas na Região Serrana, agrega diferentes modalidades de turismo, com a presença de fazendas, do turismo ecológico (trilhas) e de aventura em espaços rurais, além do histórico-cultural no perímetro urbano.

3.2- Rural: localidades situadas em diferentes regiões do interior fluminense, desenvolvendo atividades turísticas em zona rural, através de hotéis-fazenda (Moura, 2001), muitas vezes resgatando a vida rural através de simulacros em antigas fazendas de café refuncionalizadas.

\footnotetext{
${ }^{6}$ Entendemos por fixo social, segundo Santos (1988: 77-78), as obras produzidas pela ação humana.
} 
3.3- Rural/Ecológica/Aventura: localidades situadas, em sua maioria, em áreas serranas do estado, desenvolvendo atividades voltadas para o turismo rural (hotéisfazenda, pesque-pague, cavalgadas), ecológico (trilhas, caminhadas), além do turismo alternativo (escaladas, corredeiras etc.).

\section{Estância/Rural}

Localidades que conjugam a modalidade de turismo-estância, com a presença de fontes termais, descanso; além de hotéis-fazenda.

\section{Cultural/Rural}

Este tipo agrega um caso particular, priorizando uma vila do município de Valença - Conservatória - na qual se destaca por apresentar atividade turística voltada para a música (serestas), constituindo-se em uma tradição para os apreciadores deste tipo de lazer. Afora isto, o distrito oferece outras opções associadas ao turismo rural, como equitação, pesca e artesanato.

\section{Apoio ao Turismo}

Algumas localidades do Estado, apesar de não apresentarem a função turística como atividade importante, exercem atividades de apoio em decorrência da presença de hospedagem e por estarem próximas de localidades turísticas.

Algumas poderão, no futuro, passar por um processo de turistificação, em decorrência de seu potencial e da presença de condicionantes naturais e históricos. A modalidade de turismo rural, de aventura e ecológico poderá ser incrementada, além de outras.

Elas exercem a função de apoio (infra-estrutura), geralmente localizadas em eixos rodoviários importantes, facilitando o acesso àquelas com funções turísticas, mas que apresentam infra-estrutura precária, notadamente no que diz respeito à hospedagem.

A partir da elaboração da tipologia analisada, procurou-se aplicá-la para as localidades fluminenses, conforme indicado no QUADRO 2, que apresenta as respectivas localidades, segundo a classificação por tipos e sub-tipos e sua respectiva localização no espaço fluminense. 


\section{QUADRO 2 \\ ESTADO DO RIO DE JANEIRO - TIPOLOGIA DAS LOCALIDADES COM ATIVIDADES TURÍSTICAS E DE APOIO, 1999.}

\begin{tabular}{|c|c|c|}
\hline TIPOLOGIA (FUNÇÕES) & LOCALIDADES & REGIÕES DE GOVERNO \\
\hline $\begin{array}{l}\text { 1- Litorânea } \\
\text { 1.1- Diversificada }\end{array}$ & $\begin{array}{l}\text { 1- Rio de Janeiro* } \\
\text { 2- Niterói* }\end{array}$ & Metropolitana \\
\hline \multirow[t]{2}{*}{ 1.2- Praia-Náutica/Rural } & 3-Maricá* & Metropolitana \\
\hline & 4- Campos dos Goytacazes* & Norte Fluminense \\
\hline \multirow[t]{3}{*}{ 1.3- Praia-Náutica } & $\begin{array}{l}\text { 5- Araruama* } \\
\text { 6- Rio das Ostras* } \\
\text { 7- Armação dos Búzios* } \\
\text { 8- Arraial do Cabo* } \\
\text { 9- São Pedro da Aldeia* } \\
\text { 10- Saquarema* }\end{array}$ & Baixadas Litorâneas \\
\hline & $\begin{array}{l}\text { 11-Ilha Grande* (Vila do Abraão } \\
\text { - distrito de Angra dos Reis) }\end{array}$ & Baía da Ilha Grande \\
\hline & $\begin{array}{l}\text { 12- Itacuruçá* (distrito de } \\
\text { Mangaratiba) } \\
\text { 13- Mangaratiba* }\end{array}$ & Metropolitana . \\
\hline \multirow[t]{3}{*}{ 1.4- Praia-Náutica/Histórica } & $\begin{array}{l}\text { 14- Angra dos Reis* } \\
\text { 15- Parati* }\end{array}$ & Baía da Ilha Grande \\
\hline & 16- Cabo Frio* & Baixadas Litorâneas \\
\hline & 17-Macaé* & Norte Fluminense \\
\hline \multirow[t]{2}{*}{ 2- Histórica/Rural } & 18- Petrópolis* & Serrana \\
\hline & $\begin{array}{l}\text { 19- Vassouras* } \\
\text { 20- Barra do Piraí } \\
\text { 21- Valença }\end{array}$ & Médio Paraíba \\
\hline $\begin{array}{l}\text { 3- Rural/Ecológica/Aventura } \\
\text { 3.1- Diversificada }\end{array}$ & $\begin{array}{l}\text { 22- Nova Friburgo* } \\
\text { 23-Teresópolis* }\end{array}$ & Serrana \\
\hline \multirow[t]{2}{*}{ 3.2-Rural } & $\begin{array}{l}\text { 24- Casimiro de Abreu } \\
\text { 25- Rio Bonito } \\
\text { 26- Engenheiro Passos* } \\
\text { (distrito de Resende) } \\
\text { 27- Quatis }\end{array}$ & $\begin{array}{l}\text { Baixadas Litorâneas } \\
\text { Médio Paraíba }\end{array}$ \\
\hline & $\begin{array}{l}\text { 28- Miguel Pereira* } \\
\text { 29- Eng. Paulo de Frontin } \\
\text { 30- Paty do Alferes* } \\
\text { 31- Mendes* }\end{array}$ & Centro-Sul Fluminense \\
\hline
\end{tabular}




\begin{tabular}{|c|c|c|}
\hline \multirow[t]{4}{*}{ 3.3- Rural/Ecológica/Aventura } & 32- Três Rios & Centro-Sul Fluminense \\
\hline & $\begin{array}{l}\text { 33- Itatiaia* } \\
\text { 34- Visconde de Mauá* } \\
\text { (distrito de Resende) } \\
\text { 35- Penedo } \\
\text { (distrito de Itatiaia) }\end{array}$ & Médio Paraíba \\
\hline & $\begin{array}{l}\text { 36- Sana } \\
\text { (Distrito de Macaé) }\end{array}$ & Norte Fluminense \\
\hline & 37- Cachoeiras de Macacu & Baixadas Litorâneas \\
\hline \multirow[t]{2}{*}{ 4- Estância/Rural } & 38- Paraíba do Sul* & Centro-Sul Fluminense \\
\hline & $\begin{array}{l}\text { 39- Santo Antônio de Pádua* } \\
\text { 40- Raposo* } \\
\text { (distrito de Itaperuna) }\end{array}$ & Noroeste Fluminense \\
\hline 5- Cultural/Rural & $\begin{array}{l}\text { 41- Conservatória* } \\
\text { (distrito de Valença) }\end{array}$ & Médio Paraíba \\
\hline \multirow[t]{3}{*}{ 6- Apoio ao Turismo } & $\begin{array}{l}\text { Barra Mansa } \\
\text { Volta Redonda } \\
\text { Resende }\end{array}$ & Médio Paraíba \\
\hline & $\begin{array}{l}\text { Carmo } \\
\text { Santa Maria Madalena } \\
\text { Trajano de Morais* } \\
\text { Porciúncula } \\
\end{array}$ & $\begin{array}{l}\text { Serrana } \\
\text { Noroeste Fluminense }\end{array}$ \\
\hline & Itaguaí & Metropolitana \\
\hline
\end{tabular}

* Classificadas como de função turística pelo Guia Quatro Rodas, 1999.

Elaborado por: RIBEIRO, M. Angelo, 2000/2001.

\section{CONSIDERAÇÕES FINAIS}

O turismo é um tema emergente e de grande pertinência, por se tratar de uma expressiva atividade econômica, muito diversificada e fragmentada, pois inclui diferentes modalidades e infra-estrutura representadas pelos diversos tipos de hospedagem, restaurantes e outros serviços na área de alimentação, serviços e instalações ligadas aos transportes, divertimentos, atrações e instalações para o lazer em geral, lojas de souvenirs e um grande número de outros empreendimentos.

Neste sentido, a atividade turística, fenômeno complexo, envolve outros fenômenos sociais, culturais e econômicos da sociedade contemporânea, produzindo lugares para o consumo de bens, serviços e paisagens.

O turismo é um fenômeno sócio-espacial, e sendo assim, pensar o turismo sem as bases geográficas não se faz turismo, além de pensar que esta atividade consome as paisagens. Fenômeno típico da modernidade e do processo de urbanização, o turismo está inserido no contexto do lazer. Sendo assim, para os geógrafos, é mais um tema a ser estudado, a partir dos aspectos espaciais (organização e impactos), além 
das locações e dos fluxos das viagens, da dispersão do desenvolvimento, do uso da terra e das modificações do ambiente físico (paisagens).

O turismo contemporâneo, aproveitando-se das idéias de Luchiari (1998: 18), "conduziu o imaginário coletivo a revalorizar a natureza, a cultura e mesmo o simulacro que, queiramos ou não, é natureza e cultura construídas socialmente."

Neste contexto, o Estado do Rio de Janeiro, unidade federada caracterizada por enorme diversidade de situações climáticas, topográficas, entre outras; bem como por grande variedade de condições histórico-culturais, contribui para que a atividade turística revista-se de grande importância como fator de interiorização do desenvolvimento econômico e social.

Assim, cabe ao governo do estado, às prefeituras e aos agentes privados que operam com o turismo, desenvolver projetos e implementá-los, a fim de que esta atividade possa tornar-se uma fonte de divisas para suas respectivas instâncias, aproveitando as condições naturais e histórico-culturais inerentes ao espaço fluminense.

Resumo: O objetivo principal desse artigo é o de analisar os elementos condicionantes para o desenvolvimento da atividade turística em território fluminense, além de elaborar uma tipologia para as 41 localidades (cidades e vilas), com funções turísticas, considerando-se: a classificação da função turística, as atrações e eventos, e os tipos de hospedagem. Com base nestes elementos, distinguiu-se cinco tipos de localidades: Litorânea, Histórico/Rural, Rural/Ecológica e Aventura, Estância/Rural e Cultural/Rural. Isto posto, a atividade turística se reveste de grande importância como fator de interiorização do desenvolvimento econômico e social e o Estado do Rio de Janeiro, em decorrência de suas condições naturais e histórico-culturais, permite a promoção dessa atividade em seu território.

Palavras-chave: atividade turística; território fluminense; tipologia.

Abstract: The presente article seeks to analyse the conditionant elements to the development of the touristic activity at fluminense territory, yonder the elaboration of a typology to the 41 localities (cities and villages), with touristic functions, considering: the arrangement of touristic functions, the attactions and events, and the types of lodgings. Based on these elements, it was distinguished five types of localities: Coastal, Historical/Rural, Rural/Ecological and Adventure, Country Seat/Rural and Cultural/Rural. Thus, the touristc activity shows a great importance to the interiorization of the economic and social development and the State of Rio de Janeiro, through its natural and historiccultural conditions, makes possible the promotion of this activity on its territory.

Keywords: touristic activity; "fluminense" territory; typology.

\section{BIBLIOGRAFIA}

BOFF, Claudete e GONÇALVES, Ana Beatriz R. (Orgs.) 2001. Turismo e cultura. A história e os atrativos regionais. Santo Ângelo: URI/FAPERGS. 166p.

CASTROGIOVANNI, Antonio Carlos 2000. Turismo e ordenação no espaço urbano. In: CASTROGIOVANNI, Antonio Carlos (Org.). Turismo urbano. São Paulo: Contexto, pp.23-32, 111p.

CIDE .1997. Estado do Rio de Janeiro: território. Rio de Janeiro: CIDE, 80p.

EMBRATUR. 1999. Anuário Estatístico. Brasília, v. 26.

FRATUCCI, Aguinaldo César. 2000) O ordenamento territorial da atividade turísti- 
ca no Estado do Rio de Janeiro. Processos de inserção dos lugares turísticos nas redes do turismo. Niterói: UFF/Programa de Pós-Graduação em Geografia, 177p (Dissertação de Mestrado).

GUIA QUATRO RODAS. 1999. Brasil. São Paulo: Editora Abril, 513p.

ISTO É. 2001. Férias no Brasil. Sudeste. São Paulo: Editare Editora/Empresa das Artes, 34p.

JORNAL DO BRASIL. 2001. Rio: roteiros de viagem. Rio de Janeiro, 26/01/2001. Férias de verão. 2001. In: Revista de Programa. Rio de Janeiro, 26/10 a $1 / 11 / 2001$, p. $24-45$.

. Turismo comemora boa fase. 2001. Rio de Janeiro, 23/11/2001, p. 18.

LUCHIARI, Maria Tereza D. P. 1998. Urbanização turística: um novo nexo entre o lugar e o mundo. In: LIMA, Luiz Cruz (Org.). Da cidade ao campo: a diversidade do saber-fazer turístico. Fortaleza: FUNECE, pp. 15-29.

MOURA, Antônio Márcio Ferreira de. 2001. Turismo, meio ambiente e espaço rural. In: FUNARI, Pedro Paulo e PINSKY, Jaime (Orgs.). Turismo e patrimônio cultural. São Paulo: Contexto, pp, 67-78, 103p.

RAHY, Ione Salomão. 1999. Povoamento do Estado do Rio de Janeiro. GEOUERJ. Departamento de Geografia, UERJ, Rio de Janeiro, nº. 6, pp. 37-43.

RIBEIRO, Miguel Angelo. 2001. Considerações sobre o espaço fluminense: estrutura e transformações. Departamento de Geografia: UERJ, (mịmeo).

RIBEIRO, Miguel Angelo e O'NEILL, Maria Mônica Vieira Caetano. 2001. Atlas do Estado do Rio de Janeiro. (inédito).

RODRIGUES, Adyr Balastreri. 2001. Geografia do turismo: novos desafios. In: TRIGO, Luiz Gonzaga Godói (Org.). Turismo. Como aprender, como ensinar. São Paulo: Editora SENAC, pp. 87-122, 320p.

RODRIGUES, Marly. 2001. Preservar e consumir: o patrimônio histórico e o turismo. In: FUNARI, Pedro Paulo e PINSKY, Jaime (Orgs.). Turismo e patrimônio cultural. São Paulo: Contexto, pp. 13-24, 103p.

SANTOS, Milton. 1988. Metamorfoses do espaço habitado. São Paulo: HUCITEC, $124 \mathrm{p}$.

THEOBALD, William F. (Org.). 2001. Turismo global. São Paulo: Editora SENAC, $510 \mathrm{p}$.

TURISRIO. 1999. Plano Diretor de Turismo: diagnóstico preliminar. Rio de Janeiro: TurisRio.

YÁZIGI, Eduardo. 2001. A alma do lugar: turismo, planejamento e cotidiano em litorais e montanhas. São Paulo: Contexto, 301p. 